\title{
Pengaruh Desain dan Inovasi Produk Terhadap Kepuasan Konsumen dan Dampaknya pada Loyalitas Konsumen (Studi Kasus pada Konsumen Lipstik Wardah Kosmetik Jabodetabek)
}

\author{
Melani Quintania ${ }^{1}$ Sasmitha ${ }^{2}$ \\ Manajemen, Fakultas Ekonomi, Universitas Darma Persada, Jakarta ${ }^{1,2}$ \\ melani_quintania@fe.unsada.ac.id ${ }^{1}$, sasmitha1988@gmail.com²
}

\begin{abstract}
Abstrak
Penelitian ini bertujuan untuk mengetahui pengaruh desain dan inovasi produk terhadap kepuasan konsumen serta dampaknya pada loyalitas konsumen pada produk lipstik wardah kosmetik di wilayah Jabodetabek. Penelitian ini merupakan jenis eksplanatori (explanatory research) yang menggunakan pendekatan kuantitatif yang berupa observasi dan hasilnya menggunakan data primer berupa survei kepada konsumen. Penentuan sampling menggunakan syarat kepada konsumen yaitu minimal 3 (tiga) kali pembelian dalam 5 (lima) bulan terakhir, berusia 17 tahun, dan mempunyai kemampuan untuk memahami dan mengisi kuesioner yang diterapkan sehingga diperoleh sampel akhir sebanyak 200 responden. Metode analisis data menggunakan analisis jalur dan menggunakan program SPSS (Statistical Package for The Social Science). Hasil penelitian ini membuktikan bahwa desain dan inovasi produk memiliki pengaruh positif dan signifikan terhadap kepuasan konsumen dan kepuasan konsumen memiliki pengaruh positif dan signifikan terhadap loyalitas konsumen. Desain dan inovasi produk memiliki pengaruh langsung terhadap loyalitas konsumen sementara tidak memiliki pengaruh signifikan terhadap loyalitas konsumen melalui kepuasan konsumen.
\end{abstract}

Kata Kunci: desain, inovasi produk, kepuasan konsumen, loyalitas konsumen.

\section{Effect of Product Design and Innovation on Consumer Satisfaction and its Impact on Consumer Loyalty (Case Study on Lipstick Consumer Wardah Cosmetics Jabodetabek)}

\begin{abstract}
This study aims to determine the effect of the design, product innovation on consumer satisfaction and its impact on consumer loyalty to Wardah cosmetic lipstick products in region of Jabodetabek. This research is an explanatory type of research that uses a quantitative approach in the form of observation. The results use primary data in the way of surveys to consumers. Sampling determines using conditions for consumers, namely at least three purchases in the last five months, 17 years old, and can understand and fill out the questionnaire applied to obtain a final sample of 200 respondents. The data analysis method uses path analysis and uses the SPSS (Statistical Package for The Social Science) program. The results of this study prove that product design and innovation have a positive and significant effect on customer satisfaction and customer satisfaction has a positive and significant impact on customer loyalty. Product design and innovation have a direct influence on consumer loyalty while not having a substantial effect on consumer loyalty through customer satisfaction.
\end{abstract}

Keywords: design, product innovation, customer satisfaction, customer loyalty.

\section{PENDAHULUAN}

Pasar industri kecantikan Indonesia merupakan pasar ketiga terbesar di Asia. Peluang besar menanti para pelaku industri kecantikan untuk berjaya di dunia internasional. Populasi penduduk Indonesia yang merupakan terbesar keempat di dunia, dianggap sebagai peluang besar di dunia kecantikan (ika/JPC, 2017). Sebagai negara beriklim tropis, serta kaya akan warisan kecantikan, keberagaman suku bangsa dan budaya, menjadi keunikan tersendiri bagi pengembangan industri kosmetik dan perawatan kecantikan yang potensial. 
Industri kosmetik merupakan salah satu industri yang strategis dan potensial mengingat bahwa saat ini terdapat 760 perusahaan kosmetik skala besar, menengah, dan kecil yang tersebar di wilayah Indonesia, serta mampu menyerap 75.000 tenaga kerja secara langsung dan 600.000 tenaga kerja secara tidak langsung (Susilawati, 2016).

Berdasarkan Peraturan Pemerintah Nomor 14 Tahun 2015 tentang Rencana Induk Pembangunan Industri Nasional (RIPIN) tahun 2015-2035, industri kosmetik menjadi salah satu industri andalan, yaitu industri prioritas yang berperan besar sebagai penggerak utama (prime mover) perekonomian. Selain menekankan pada penguasaan riset dan teknologi untuk mendukung inovasi produk kosmetik, diharapkan pula terciptanya kemandirian bahan baku kosmetik, terutama berbasis alam Indonesia (Rahayu, 2016). Penampilan yang menarik adalah dambaan setiap orang yang menjadi target pasar para pelaku bisnis atau produsen kosmetik dengan populasi penduduk sekitar 250 juta jiwa menjadi sesuatu yang sangat menjanjikan (Fitriani \& Sharif, 2018). Berikut sepuluh produk kosmetik wanita paling populer di Indonesia selama tahun 2018:

\section{Tabel 1}

Format Tabel

\begin{tabular}{ll}
\hline No & Merek \\
\hline 1. & Wardah \\
\hline 2. & Make Over \\
\hline 3. & Inez \\
\hline 4. & Pac \\
\hline 5. & Purbasari \\
\hline 6. & Emina \\
\hline 7. & Sariayu \\
\hline 8. & Mustika Ratu \\
\hline 9. & Viva Cosmetics \\
\hline 10. & Lt Pro \\
\hline Sumber: (Highlight Media, 2018)
\end{tabular}

Saat ini, merek kecantikan asli buatan Indonesia semakin banyak bermunculan. Hal itu memberikan angin segar bagi berkembangnya brand kosmetik lokal agar mampu bersaing dengan merek global. Beberapa brand kosmetik lokal Indonesia sudah sangat lama dikenal masyarakat seperti sariayu, mustika ratu atau viva. Hadirnya brand kosmetik Indonesia baru seperti wardah, inez cosmetics atau emina menjadi alternatif pilihan bagi konsumen. Wardah cosmetics adalah salah satu pelopor kosmetik yang berlabel halal di Indonesia. Pendiri Wardah cosmetics adalah Nurhayati Subakat. Wanita yang lahir di Padang Panjang, Sumatera Barat, 27 Juli 1950 itu seorang pengusaha kosmetik asal Indonesia. Sebagai pendiri PT Pusaka Tradisi Ibu yang kini telah berubah menjadi PT Paragon Technology and Innovation, mengelola merek kosmetik wardah, make over, dan perawatan rambut putri. Wardah cosmetics adalah produk kecantikan wanita Indonesia yang aman dan berkualitas tinggi dengan memproduksi ragam kosmetik untuk bermacam jenis kulit. Wardah cosmetics aman bagi kulit karena terbuat dari bahan-bahan alami terpecaya. Selain itu, merek ini juga merupakan kosmetik yang halal (Wardah Kosmetik, 2019; Anggraini, Kustiyah, \& Sudarwati, 2019).

Tabel 2

Winner ICSA 2016-2017 (Indonesian Customer Satisfaction Award)

\begin{tabular}{llll}
\hline \multicolumn{2}{c}{2016} & \multicolumn{2}{c}{2017} \\
\hline Product Category & Merk/Brand & Product Category & Merk/Brand \\
\hline Lipstick & Wardah & Lipstick & Wardah \\
\hline Loose Skin Powder & Wardah & Loose Skin Powder & Wardah \\
\hline Compact Skin Powder & Wardah & Compact Skin Powder & Wardah \\
\hline
\end{tabular}

Sumber: (ICSA, 2019) 
Menurut data di atas, dapat disimpulkan bahwa wardah menjadi salah satu produk yang banyak dikonsumsi oleh masyarakat Inonesia, wardah berhasil mempertahankan ektistensinya di industri kosmetik dengan terus meraih penghargaan salah satu nya liptik wardah kosmetik, dengan meraih penghargaan tersebut menunjukan bahwa adanya respon positif terhadap kepuasan konsumen. Menurut Kotler, desain dapat membentuk atau memberikan atribut pada suatu produk, sehingga dapat menjadi ciri khas pada merek suatu produk. Ciri khas dari suatu produk tersebut pada akhirnya akan dapat membedakannya dengan produk-produk sejenis merek lain dari pesaing (Ansah, 2017). Masda menambahkan bahwa kunci utama untuk memenangkan persaingan adalah dengan menciptakan inovasi, inovasi harus diciptakan perusahaan karena inovasi adalah salah satu sumber pertumbuhan perusahaan. Inovasi produk adalah salah satu faktor yang paling diandalkan oleh seoeang pemasar dalam memasarkan suatu produk. Inovasi akan meningkatkan nilai tambah suatu produk, inovasi akan menciptakan suatu produk baru yang dapat memberikan solusi yang lebih baik bagi pemecahan masalah yang dihadapi konsumen (Dwi Putra \& Ekawati, 2017).

Loyalitas terjadi karena kepuasan pelanggan terhadap produk yang melebihi harapan konsumen. Konsumen dapat dikatakan loyal jika konsumen tersebut tetap setia membeli produk dan melakukan pembelian ulang secara konsisten bahkan sampai merekomendasikannya kepada orang lain. Kepuasan konsumen merupakan keinginan pelanggan untuk terus berlangganan pada perusahaan dalam jangka panjang dan merekomendasikan produk tersebut kepada teman dan kolega. Loyalitas konsumen adalah sikap konsumen yang setia membeli produk secara konsisten atau secara berulang-ulang dan merekomendasikannya kepada orang lain (Lovelock \& Wirtz, 2011, hal. 338). Adanya desain dan Inovasi yang dilakukan wardah kosmetik akan berdampak pada loyalitas konsumennya dan akan membuat sebuah persepsi baru terhadap citra merek yang telah dibangun selama ini. Tabel 3 di bawah ini menjelaskan keluhan ketidakpuasan konsumen wardah kosmetik dapat dilihat dari hasil pemakaian produk wardah tersebut dan pengguna tidak puas

Tabel 3

Beberapa Contoh Keluhan Ketidakpuasan Konsumen Lipstik Wardah

\begin{tabular}{|c|c|c|c|}
\hline No & Nama & Keluhan & Sumber \\
\hline 1 & sabrinaelfianisa & $\begin{array}{l}\text { packaging : packaging wardah rasanya ya } \\
\text { gitu, bagus tp ga yg bagus banget, tapi elegan. } \\
\text { aplikatornya juga enak tekstur : creamy, } \\
\text { hasilnya matte bgt, saran aja kalau mau pake } \\
\text { wardah ini harus banget pake lipbalm } \\
\text { sebelumnya soalnya walaupun ringan tp } \\
\text { lumayan bikin kering kalau menurutku, } \\
\text { lumayan tahan lama juga }\end{array}$ & $\begin{array}{l}\text { reviews.femaledaily.com } \\
\text { (21 Agustus 2019) }\end{array}$ \\
\hline 2 & siamuktazzah & $\begin{array}{l}\text { Dulu aku juga pake rangkaian produk dari } \\
\text { Wardah,tapi mungkin aku ga cocok jadi } \\
\text { mamaku bilang ga usah lanjutkan } \\
\text { pemakaiannya,wajah jadi kusam }\end{array}$ & $\begin{array}{l}\text { www.beautynesia.id } \\
\text { (oktober 2019) }\end{array}$ \\
\hline 3 & $\begin{array}{l}\text { Artikel } \\
10 \text { kelebihan dan } \\
\text { kekurangan Wardah } \\
\text { white secret day } \\
\text { cream" }\end{array}$ & $\begin{array}{l}\text { Produk wardah memiliki kekurangan yang } \\
\text { diantara nya effect tone up kurang pas dengan } \\
\text { kulit sawo matang dan kandungan spf pada } \\
\text { produk wardah kurang banyak yang arti nya } \\
\text { inovasi pada produk wardah kurang beragam } \\
\text { khusus nya pada keberagaman shade } \\
\text { kosmetik tersebut }\end{array}$ & tokopedia.com \\
\hline
\end{tabular}

Adapun permasalahan dalam penelitian ini adalah kepuasan dari konsumen cenderung tidak baik, dilihat dari adanya keluhan serta laporan dari para konsumen terhadap wardah kosmetik serta inovasi produk wardah kurang beragam, khususnya pada pilihan shade warna dan kandungan spf yang dimiliki produk wardah. Berdasarkan permasalahan tersebut, maka dapat dibuat rumusan masalah bagaimana pengaruh secara langsung antara desain dan inovasi produk terhadap kepuasan dan loyalitas konsumen, pengaruh langsung antara kepuasan konsumen terhadap loyalitas konsumen, dan pengaruh secara tidak langsung antara desain dan inovasi produk terhadap loyalitas melalui kepuasan konsumen 


\section{TINJAUAN PUSTAKA}

Manajemen pemasaran adalah proses perencanaan dan pelaksanaan dari perwujudan, pemberian harga, jasa, dan gagasan untuk menciptakan pertukaran dengan kelompok sasaran yang memenuhi tujuan pelanggan dan organisasi (Abdullah \& Tantri, 2015, hal. 22). Lebih lanjut, Kotler menyatakan bahwa manajemen pemasaran adalah proses perencanaan dan pelaksanaan pemikiran, penetapan harga, promosi serta penyaluran gagasan, barang dan jasa untuk menciptakan pertukaran yang memuaskan tujuan-tujuan individu dan organisasi (Purba, 2017, hal. 5).

Kotler mendefinisikan desain produk yaitu: "design is the totality of features that affect how a product look, feels, and function to a consumer.", hal ini berarti bahwa desain merupakan totalitas fitur yang memengaruhi bagaimana sebuah produk terlihat, terasa, dan berfungsi bagi konsumen. The Lieven yang berjudul "the Effect Of Brand Design in Brand Gender Perceptions and Brand Prefereance" mengatakan bahwa elemen-elemen desain pada merek secara konsisten memengaruhi persepsi maskulinitas dan femininnitas dari sebuah merek dan hal tersebut erat hubungannya dengan ekuitas merek yang indikator di dalamnya terdapat citra merek pada sebuah produk (Ayuningtyas, 2016).

Menurut Kotler, inovasi adalah produk atau jasa yang dipersepsikan oleh konsumen sebagai produk atau jasa baru. Secara sederhana, inovasi dapat diartikan sebagai terobosan yang berkaitan dengan produkproduk baru, inovasi tidak hanya terbatas pada pemikiran bisnis baru dan proses baru. Oleh sebab itu maka perusahaan diharapkan menciptakan pemikiran-pemikiran baru, gagasan baru yang menawarkan produk inovatif serta memberikan pelayanan yang memuaskan bagi pelanggan. Inovasi semakin memiliki arti penting bukan saja sebagai suatu alat untuk mempertahankan kelangsungan hidup perusahaan melainkan juga untuk unggul dalam persaingan (Sinurat, Lumanauw, \& Rori, 2017). Menurut Gitosudarmo, penciptaan produk baru inovasi produk sebenarnya meliputi hal yaitu: (1) Produk yang sama sekali baru, (2) Perubahan desain (redesign); dan (3) Pembungkusan (packaging) (Santoso \& Samboro, 2017).

Menurut Tjiptono dan Chandra, kepuasan merupakan elemen penting yang mencerminkan keberhasilan dari produsen ataupun penyedia jasa. Kata kepuasan (satisfaction) berasal dari bahasa latin satis (artinya cukup baik, mamadai) dan facio (melakukan atau membuat), sehingga kepuasan bisa diartikan sebagai upaya pemenuhan sesuatu atau membuat sesuatu memadai (Molle, Mandey, \& Kojo, 2019). Lebih lanjut, kepuasan konsumen merupakan hal yang wajib bagi setiap organisasi bisnis dan nirlaba, konsultasi bisnis, peneliti pemasaran, eksekutif bisnis, dan dalam konteks tertentu, para birokrat dan politisi. Hasil studi berkesinambungan di bidang pemasaran bahwa kepuasan pelanggan berkaitan dengan ukuran kinerja finansial seperti peningkatan laba (Wahyu \& Gorda, 2019). Lima faktor utama yang harus diperhatikan dalam menentukan yaitu: (1) kualitas produk, pelanggan akan merasa puas bila hasil evaluasi mereka menunjukakan bahwa produk yang mereka gunakan berkualitas; (2) kualitas pelayanan, pelanggan akan merasa puas bila mereka mendapatkan pelayanan yang baik atau sesuai dengan diharapkan; (3) emosional mencakup kepuasan yang diperoleh berasal dari nilai sosial yang membuat pelanggan menjadi puas terhadap merek tertentu; (4) harga, produk yang mempunyai kualitas yang sama tetapi menetapkan harga yang relatif murah akan memberikan nilai yang lebih tinggi kepada pelanggan; dan (5) biaya, pelanggan akan merasa puas apabila ia tidak perlu mengeluarkan biaya tambahan atau tidak perlu membuang waktu untuk dapat memperoleh barang dan jasa (Khairani, Siregar, Hutabalian, \& Karolina, 2019).

Menurut Almana, dkk., loyalitas pelanggan adalah suatu perilaku pembelian pengulangan yang telah menjadi kebiasaan, yang mana telah ada keterkaitan dan keterlibatan tinggi pada pilihan pelanggan terhadap objek tertentu, dan bercirikan dengan ketiadaan pencarian informasi eksternal dan evaluasi alternatif (Wahyuni, 2019). Loyalitas konsumen merupakan ketetapan seseorang dalam bertahan menjadi pelanggan serta senantiasa melakukan pembelian ulang atas produk atau jasa yang diinginkan secara terus menerus dari waktu ke waktu walaupun sistem pemasaran dapat mengubah potensi, perilaku seseorang dalam bertindak seperti yang dikutip dalam Oliver. Loyalitas menggambarkan kesetiaan pelanggan untuk terus setia pada perusahaan akan produk atau jasa secara terus menerus serta merekomendasikan kepada produsen (Nurbani, Mulyanto, \& Wardani, 2019). Dimensi loyalitas konsumen mencakup: (1) Melakukan pembelian berulang, (2) Membeli antar lini produk atau jasa (Purchase Across Product and Service Lines); (3) Mereferensikan kepada orang lain (Refers Other); dan (4) Menunjukkan kekebalan terhadap terikan dari pesaing (demonstates an Immunity To The Full of The Competition) (Griffin, 2010). 


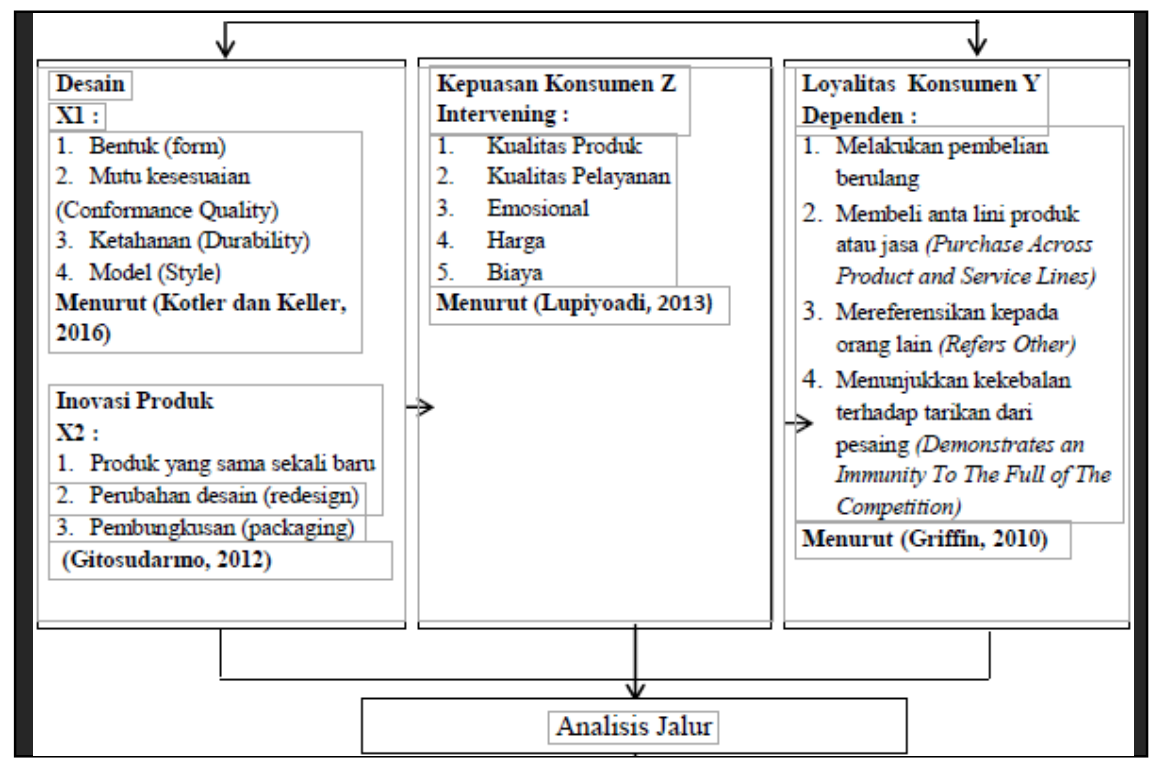

Gambar 1. Paradigma Penelitian

Paradigma penelitian di atas digunakan untuk menjawab perumusan masalah dan kajian empiris yang dilakukan sebelumnya yang diturunkan ke dalam rumusan hipotesis sebagai berikut:

$\mathrm{H}_{1}$ : Terdapat Pengaruh anatara desain (X1) dan inovasi (X2) produk terhadap kepuasan konsumen (Z)

$\mathrm{H}_{2}:$ Terdapat pengaruh antara desain (X1) dan inovasi (X2) terhadap loyalitas konsumen (Y)

$\mathrm{H}_{3}$ : Terdapat pengaruh antara kepuasan konsumen $(\mathrm{Z})$ terhadap loyalitas konsumen ( $\mathrm{Y}$ )

$\mathrm{H}_{4}$ : Terdapat pengaruh anatara desain (X1) dan inovasi produk (X2) terhadap loyalitas konsumen (Y) melalui kepuasan konsumen $(\mathrm{Z})$

\section{METODE PENELITIAN}

Penelitian ini merupakan jenis eksplanatori (explanatory research) adalah untuk menguji antar variabel yang dihipotesiskan. Penelitian ini terdapat hipotesis yang akan diuji kebenarannya. Hipotesis ini menggambarkan hubungan antara dua variabel, untuk mengetahui apakah variabel berasosiasi atau tidak dengan variabel lainnya atau apakah variabel disebabkan atau dipengaruhi atau tidak oleh variabel lainnya (Sani \& Maharani, 2013). Penelitian ini menggunakan pendekatan kuantitatif yang berupa observasi dan hasilnya menggunakan data primer berupa survei kepada konsumen. Penelitian ini dilakukan di wilayah Jabodetabek, sedangkan objek dalam penelitian ini adalah pelanggan kosmetik wardah. Penetapan sampel dalam penelitian ini harus representative (mewakili), yaitu sampel yang mencerminkan populasinya. Ukuran populasi dalam penelitian ini sangat banyak dan belum diketahui dengan pasti sehingga dihitung rumus perhitungan berikut ini:

$$
n=\frac{z^{2}}{4(M o e)^{2}}
$$

Keterangan :

$\mathrm{n} \quad=$ ukuran sampel

$\mathrm{z}=$ skor pada tingkat signifikansi tertentu (derajat keyakinan ditentukan $95 \%$

maka $\mathrm{z}=1,96$

Moe $=$ margin of error, tingkat kesalahan maksimum adalah $5 \%$

(Widiyanto, 2008)

$$
n=\frac{(1.96)^{2}}{4(5 \%)^{2}}
$$

Dalam penelitian ini, sampel $(\mathrm{n}=96,04=97)$ atau dibulatkan menjadi 100 responden yang ditetapkan adalah konsumen kosmetik wardah yang melakukan pembelian minimal 3 kali dalam 5 bulan terakhir, berusia 17 tahun, dan mempunyai kemampuan untuk memahami dan mengisi kuesioner yang diterapkan. 
Sumber data penelitian ini meliputi data primer yaitu data yang diperoleh kuesioner pada konsumen yang menggunakan kuesioner, kuesioner tersebut memuat pertanyaan mengenai data diri responden serta pernyataan dari indikator setiap variabel yang digunakan dalam penelitian ini. Variabel-variabel tersebut diukur dengan menggunakan skala likert yang terdiri dari 5 tingkatan dengan masing-masing kriteria:

\section{Tabel 4 Skala Likert}

\begin{tabular}{ll}
\hline Kategori & Skor \\
\hline Sangat Setuju (SS) & 5 \\
\hline Setuju (S) & 4 \\
\hline Netral (N) & 3 \\
\hline Tidak Setuju (TS) & 2 \\
\hline Sangat Tidak Setuju (STS) & 1 \\
\hline
\end{tabular}

(Sugiyono, 2016, hal. 93)

Metode analisis data menggunakan analisis jalur (path analysis) yang berfungsi untuk menganalisis pola hubungan diantara variabel. Model ini untuk mengetahui pengaruh langsung maupun tidak langsung seperangkat variabel bebas (eksogen) terhadap varabel terikat (endogen) (Sani \& Maharani, 2013, hal. 74). Aplikasi yang digunakan untuk mengolah data yaitu program SPSS (Statistical Package for The Social Science) melalui tahapan berikut ini: (1) merancang model berdasarkan konsep dan teori pada diagram jalur. Model itu sendiri yaitu konstruksi melalui parameter spesifik yang dibatasi serta diukur baik dalam struktur, bentuk, isi, jumlah dan makna (Husain, 2019). Rancangan model pada penelitian ini yaitu:

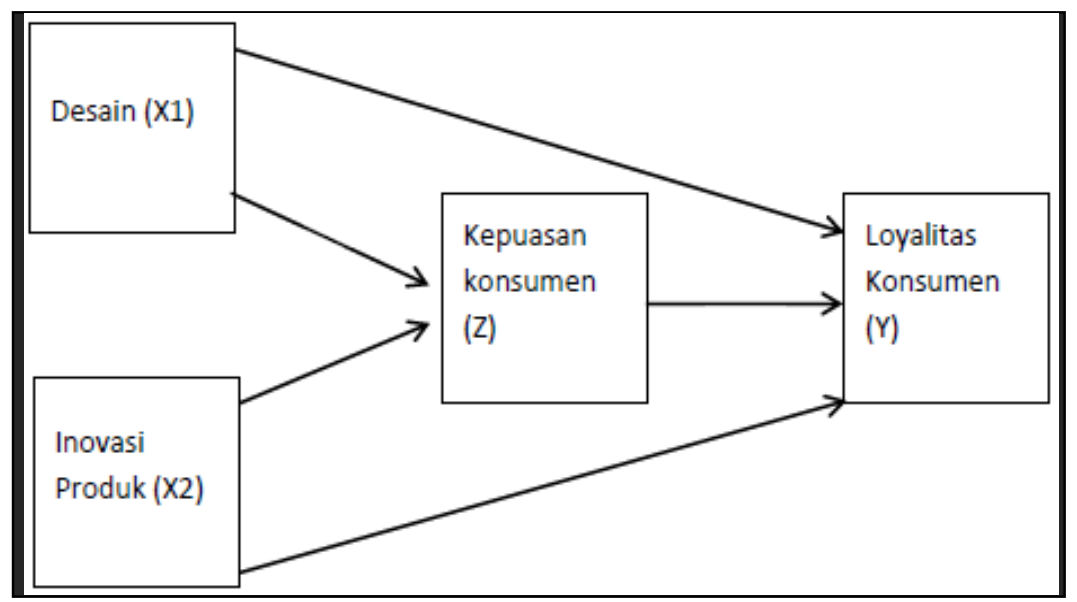

Gambar 2. Model Diagram Jalur

Selanjutnya (2) pemeriksaan terhadap asumsi yang mendasari path; (3) untuk pengujian model menggunakan triming, baik untuk uji reliabilitas konsep yang sudah ada ataupun uji pengembangan konsep baru dengan cara menghitung ulang koefisien jalur atau lebih variabel yang tidak signifikan, peneliti perlu memperbaiki model struktur analisis jalur yang telah dihipotesiskan. Uji validasi koefisien path pada setiap jalur untuk pengaruh langsung adalah sama dengan regresi, menggunakan nilai $\mathrm{p}$ dari uji t, yaitu pengujian koefisien regresi variabel dibakukan secara parsial; dan (4) intrepretasi hasil analisis (Sani \& Maharani, 2013).

\section{HASIL DAN PEMBAHASAN}

\section{Karakteristik Profil Responden}

Responden yang mengisi kuesioner dalam penelitian ini adalah sebanyak 200 orang yang pernah melakukan pembelian produk lipstik wardah kosmetik di wilayah Jabodetabek minimal 3 kali (dalam 5 bulan terakhir), berusia 17 tahun. Mayoritas responden adalah berjenis kelamin perempuan sebanyak 194 orang (97 persen), berusia dengan rentang lebih dari (>) 20-25 tahun sebanyak 129 orang $(64,5$ persen). 


\section{Uji Validitas dan Reliabilitas}

Responden yang mengisi kuesioner dalam penelitian ini adalah sebanyak 200 orang yang pernah melakukan pembelian produk lipstik wardah kosmetik di wilayah Jabodetabek minimal 3 kali (dalam 5 bulan terakhir), berusia 17 tahun. Mayoritas responden adalah berjenis kelamin perempuan sebanyak 194 orang (97 persen), berusia dengan rentang lebih dari (>) 20-25 tahun sebanyak 129 orang $(64,5$ persen).

Tabel 5

Rangkuman Hasil Uji Validitas dan Reliabilitas

\begin{tabular}{|c|c|c|c|}
\hline Items & r-hitung & $\begin{array}{l}\text { Kesimpulan } \\
\text { Uji Validitas }\end{array}$ & $\begin{array}{c}\text { Nilai Cronbach's Alpha / } \\
\text { Kesimpulan } \\
\text { Uji Reliabilitas } \\
\end{array}$ \\
\hline \multicolumn{4}{|c|}{ Variabel Desain Produk (X1) } \\
\hline $\mathrm{P} 1$ & 0,693 & valid & \multirow{8}{*}{$\begin{array}{c}0,863(\text { N of items }=8) \\
\text { lebih dari } 0,6, \text { maka } \\
\text { reliable }\end{array}$} \\
\hline $\mathrm{P} 2$ & 0,652 & valid & \\
\hline P3 & 0,736 & valid & \\
\hline P4 & 0,741 & valid & \\
\hline P5 & 0,696 & valid & \\
\hline P6 & 0,792 & valid & \\
\hline P7 & 0,666 & valid & \\
\hline P8 & 0,754 & valid & \\
\hline \multicolumn{4}{|c|}{ Variabel Inovasi Produk (X2) } \\
\hline P1 & 0,799 & valid & \multirow{6}{*}{$\begin{array}{c}0,879(\text { N of items }=6) \\
\text { lebih dari } 0,6, \text { maka } \\
\text { reliable }\end{array}$} \\
\hline $\mathrm{P} 2$ & 0,786 & valid & \\
\hline $\mathrm{P} 3$ & 0,811 & valid & \\
\hline $\mathrm{P} 4$ & 0,814 & valid & \\
\hline P5 & 0,776 & valid & \\
\hline P6 & 0,793 & valid & \\
\hline \multicolumn{4}{|c|}{ Variabel Kepuasan Konsumen (Z) } \\
\hline $\mathrm{P} 1$ & 0,799 & valid & \multirow{10}{*}{$\begin{array}{c}0,907(\text { N of items }=10) \\
\text { lebih dari } 0,6, \text { maka } \\
\text { reliable }\end{array}$} \\
\hline $\mathrm{P} 2$ & 0,720 & valid & \\
\hline P3 & 0,688 & valid & \\
\hline P4 & 0,729 & valid & \\
\hline P5 & 0,813 & valid & \\
\hline P6 & 0,813 & valid & \\
\hline P7 & 0,719 & valid & \\
\hline P8 & 0,743 & valid & \\
\hline P9 & 0,660 & valid & \\
\hline $\mathrm{P} 10$ & 0,699 & valid & \\
\hline \multicolumn{4}{|c|}{ Variabel Loyalitas Konsumen (Y) } \\
\hline $\mathrm{P} 1$ & 0,361 & valid & \multirow{8}{*}{$\begin{array}{c}0,813(\text { N of items }=8) \\
\text { lebih dari } 0,6, \text { maka } \\
\text { reliable }\end{array}$} \\
\hline $\mathrm{P} 2$ & 0,748 & valid & \\
\hline P3 & 0,702 & valid & \\
\hline P4 & 0,734 & valid & \\
\hline P5 & 0,779 & valid & \\
\hline P6 & 0,771 & valid & \\
\hline P7 & 0,792 & valid & \\
\hline P8 & 0,460 & valid & \\
\hline
\end{tabular}

Sumber: data diolah SPSS (2019)

Nilai r-tabel ditetapkan 0,1395 (df=196), hasil items (pernyataan) dan instrumen $\mathrm{X}_{1}, \mathrm{X}_{2}, \mathrm{Z} \mathrm{Y}$ masing-masing menghasilkan skor $r$ lebih besar $(>)$ dari 0,1395 pada 200 konsumen. Di samping itu, semua item dalam variabel yang diteliti memiliki nilai cronbach's alpha lebih besar ( $>$ ) dari 0,60 sehingga disimpulkan bahwa 32 (tiga puluh dua) item kuesioner adalah valid dan instrumen memiliki reliabilitas yang layak digunakan sebagai instrumen penelitian. 


\section{Hasil Path Analysis}

\section{Pengujian $\mathrm{H}_{1}$}

Tabel 6

Rangkuman Hasil Uji Koefisien Determinasi $\left(\mathbf{R}^{2}\right)$

\begin{tabular}{lcccc}
\hline Model & $\mathbf{R}$ & $\mathbf{R}^{\mathbf{2}}$ & Adjusted $\mathbf{R}^{\mathbf{2}}$ & $\begin{array}{c}\text { Std. Error of the } \\
\text { Estimate }\end{array}$ \\
\hline 1 & 0,762 & 0,580 & 0,576 & 3,417 \\
\hline
\end{tabular}

Sumber: data diolah SPSS (2019)

Nilai koefisien determinasi yang disesuaikan (Adjusted $\mathrm{R}^{2}$ ) menghasilkan skor 0,576, artinya 57,6 persen peubah atas variabel kepuasan konsumen dapat diidentifikasi oleh variabel desain dan inovasi produk sedangkan sisanya 42,4 persen diidentifikasi oleh faktor lain yang tidak diteliti.

Tabel 7

Rangkuman Hasil Uji ANOVA

\begin{tabular}{lccc}
\hline Model & df & F & Sig. \\
\hline \multirow{2}{*}{1} & 2 & 136,254 & $0,000^{\mathrm{b}}$ \\
\hline
\end{tabular}

Sumber: data diolah SPSS (2019)

Nilai ANOVA menghasilkan F Fitung sebesar 138,254 yang artinya lebih besar dari $\mathrm{F}_{\text {tabel }}$ yaitu 2,42 atau probabilitas signifikansi sebesar $0,000(0,000<0,05)$. Hasil uji ini menyatakan bahwa $\mathrm{H}_{1}$ diterima yaitu variabel desain dan inovasi produk mempunyai pengaruh yang signifikan terhadap kepuasan konsumen secara simultan.

Tabel 8

Rangkuman Hasil Uji Parsial (Uji-t)

\begin{tabular}{lcccc}
\hline & $\begin{array}{c}\text { Koefisien Regresi } \\
(\boldsymbol{\beta})\end{array}$ & $\begin{array}{c}\text { Standar } \\
\text { Koefisien }\end{array}$ & t-hitung & Signifikansi \\
\hline Constant & 12,290 & & 6,277 & 0,000 \\
\hline Desain (X1) & 0,330 & 0,256 & 3,314 & 0,001 \\
Inovasi Produk (X2) & 0,775 & 0,541 & 6,999 & 0,000 \\
\hline
\end{tabular}

Olahdata SPSS (2019)

Tabel coefficient menunjukan bahwa thitung untuk desain dan inovasi produk masing-masing sebesar 3,314 dan 6,999 (lebih besar dari $t_{\text {tabel }}=1,972$ ) atau menghasilkan probabilitas signifikan masing-masing sebesar 0,001 dan 0,000 . Berdasarkan data di atas, hipotesis penelitian ini dinyatakan diterima $\left(\mathrm{H}_{1}\right)$, artinya desain dan inovasi produk berpengaruh positif dan signifikan terhadap variabel kepuasan konsumen.

Pengujian $\mathrm{H}_{2}$ dan $\mathrm{H}_{3}$

Tabel 9

Hasil Uji Koefisien Determinasi $\left(\mathbf{R}^{2}\right)$

\begin{tabular}{lcccc}
\hline Model & $\mathbf{R}$ & $\mathbf{R}^{\mathbf{2}}$ & Adjusted $\mathbf{R}^{\mathbf{2}}$ & $\begin{array}{c}\text { Std. Error of the } \\
\text { Estimate }\end{array}$ \\
\hline 1 & 0,743 & 0,552 & 0,545 & 3,192 \\
\hline Sumber: data & diolah SPSS $(2019)$ & &
\end{tabular}

Sumber: data diolah SPSS (2019)

Nilai koefisien determinasi yang disesuaikan (Adjusted $\mathrm{R}^{2}$ ) menghasilkan skor 0,545, artinya 54,5 persen peubah atas variabel loyalitas konsumen dapat diidentifikasi oleh variabel desain dan inovasi produk serta kepuasan konsumen sedangkan sisanya 45,5 persen diidentifikasi oleh faktor lain yang tidak diteliti 
Tabel 10

Hasil Uji ANOVA

\begin{tabular}{lccc}
\hline Model & df & F & Sig. \\
\hline \multirow{2}{*}{1} & 3 & 80,468 & $0,000^{\mathrm{b}}$ \\
& 196 & & \\
\hline
\end{tabular}

Sumber: data diolah SPSS (2019)

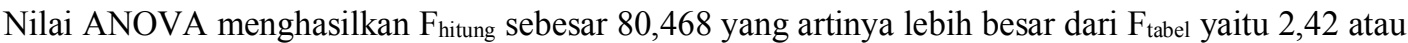
probabilitas signifikansi sebesar $0,000(0,000<0,05)$. Hasil uji ini menyatakan bahwa $\mathrm{H}_{2}$ dan $\mathrm{H}_{3}$ diterima yaitu variabel desain dan inovasi produk serta kepuasan konsumen mempunyai pengaruh yang signifikan terhadap loyalitas konsumen secara simultan.

Tabel 11

Hasil Uji Parsial (Uji t)

\begin{tabular}{lcccc}
\hline & $\begin{array}{c}\text { Koefisien Regresi } \\
(\boldsymbol{\beta})\end{array}$ & $\begin{array}{c}\text { Standar } \\
\text { Koefisien }\end{array}$ & t-hitung & Signifikansi \\
\hline Constant & 0,865 & & 0,432 & 0,666 \\
\hline Desain (X1) & 0,211 & 0,182 & 2,212 & 0,028 \\
Inovasi Produk (X2) & 0,400 & 0,309 & 3,457 & 0,001 \\
Kepuasan Konsumen (Z) & 0,290 & 0,332 & 4,357 & 0,000 \\
\hline Sumber : data dion
\end{tabular}

Sumber : data diolah SPSS (2019)

Tabel coefficient menunjukan bahwa thitung untuk desain dan inovasi produk serta kepuasan konsumen masing-masing sebesar 2,212, 3,457 dan 4,357 (lebih besar dari tabel =1,972) atau menghasilkan probabilitas signifikan masing-masing sebesar 0,028,0,001 dan 0,000. Berdasarkan data di atas, hipotesis penelitian ini dinyatakan diterima $\left(\mathrm{H}_{2}\right.$ dan $\left.\mathrm{H}_{3}\right)$ artinya desain dan inovasi produk serta kepuasan konsumen berpengaruh positif dan signifikan terhadap variabel loyalitas konsumen.

\section{Pengujian $\mathrm{H}_{4}$}

Pengujian ini bertujuan untuk membuktikan pengaruh desain, inovasi produk terhadap loyalitas melalui kepuasan konsumen dengan melihat standar koefisien pada tabel 8 dapat dirumuskan pengaruh langsung sebagai berikut :
Pengaruh Langsung
$=\mathrm{PXz}_{\mathrm{Xz}} \rightarrow 0,256$

dengan melihat standar koefisien atas kepuasan konsumen pada tabel 11 dapat dirumuskan pengaruh tidak langsung sebagai berikut :

Pengaruh Tidak Langsung

$$
\begin{aligned}
& =P_{X Z} \times P_{Y Z} \\
& =0,256 \times 0,332 \\
& =0,082
\end{aligned}
$$

\section{Pembahasan}

Pengaruh Desain $\left(\mathrm{X}_{1}\right)$ terhadap Loyalitas Konsumen (Y) melalui Kepuasan Konsumen (Z)

Pengaruh langsung yang diberikan desain terhadap loyalitas konsumen sebesar 0,182 sedangkan pengaruh tidak langsung desain melalui kepuasan konsumen terhadap loyalitas konsumen adalah 0,256 x $0,322=0,082$, maka pengaruh totalnya adalah pengaruh langsung ditambah dengan pengaruh tidak langsung yaitu: $0,182+0,082=0,264$. Berdasarkan hasil perhitungan di atas, nilai pengaruh langsung sebesar 0,182 dan pengaruh tidak langsung sebesar 0,082 berarti nilai pengaruh tidak langsung lebih kecil dibandingkan dengan nilai pengaruh langsung. Hasil ini menunjukan bahwa secara tidak langsung desain melalui kepuasan konsumen tidak mempunyai pengaruh signifikan terhadap loyalitas.
Pengaruh Langsung
$=\mathrm{P}_{\mathrm{XZ}} \rightarrow 0,541$

dengan melihat standar koefisien atas kepuasan konsumen pada Tabel 11 dapat dirumuskan pengaruh tidak langsung sebagai berikut:

Pengaruh Tidak Langsung

$$
\begin{aligned}
& =P_{X Z} \times P_{Y Z} \\
& =0,541 \times 0,332 \\
& =0,173
\end{aligned}
$$




\section{Pengaruh Inovasi Produk $\left(X_{2}\right)$ terhadap Loyalitas Konsumen (Y) melalui Kepuasan Konsumen (Z)}

Pengaruh langsung yang diberikan inovasi produk terhadap loyalitas konsumen sebesar 0,309 sedangkan pengaruh tidak langsung inovasi produk melalui kepuasan konsumen terhadap kepuasan konsumen terhadap loyalitas konsumen yaitu : $0,541 \times 0,322=0,173$, maka pengaruh totalnya adalah pengaruh langsung ditambah dengan pengaruh tidak langsung yaitu: $0,541+0,173=0,714$. Berdasarkan hasil perhitungan di atas, nilai pengaruh langsung sebesar 0,309 dan pengaruh tidak langsung sebesar 0,173 berarti nilai pengaruh tidak langsung lebih kecil dibandingkan dengan nilai pengaruh langsung. Hasil ini menunjukan bahwa secara tidak langsung inovasi produk melalui kepuasan konsumen tidak mempunyai pengaruh signifikan terhadap loyalitas konsumen.

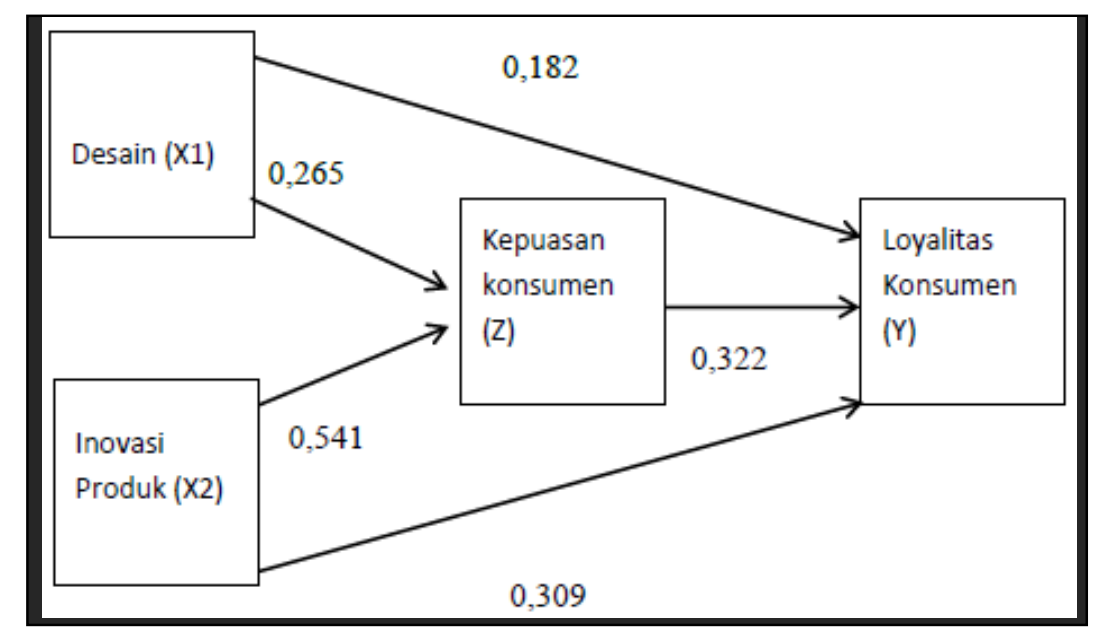

Gambar 3. Model Analisis Jalur

Pengaruh langsung antara desain dan inovasi produk terhadap kepuasan konsumen ditunjukkan oleh PXY sebesar 0,182 dan 0,309. Pengaruh langsung antara kepuasan konsumen terhadap loyalitas ditunjukkan oleh PZY sebesar 0,322 dan pengaruh langsung antara desai dan inovasi produk terhadap loyalitas konsumen ditunjukkan oleh Pxz sebesar 0,265 dan 0,541, maka pengaruh tidak langsung antara desain dan inovasi produk terhadap loyalitas konsumen melaui kepuasan konsumen yaitu (Pxz x PzY) yaitu sebesar 0,82 dan 0,173 .

\section{PENUTUP}

Hasil penelitian ini menyimpulkan bahwa desain dan inovasi produk memiliki pengaruh positif dan signifikan terhadap kepuasan konsumen. Kepuasan konsumen memiliki pengaruh positif dan signifikan terhadap loyalitas konsumen. Desain dan inovasi produk memiliki pengaruh positif dan signifikan terhadap loyalitas konsumen. Desain dan inovasi produk tidak memiliki pengaruh secara signifikan terhadap loyalitas konsumen melalui kepuasan konsumen. Adapun saran dalam penelitian ini adalah wardah hendaknya selalu berinovasi dan mengembangkan desain produk lipstik agar lebih menarik sehingga konsumen puas terhadap produk lipstik Wardah. Hal ini didukung oleh hasil penelitian bahwa desain dan inovasi produk berpengaruh terhadap kepuasan konsumen. Dalam menerapkan desain dan inovasi produk untuk mempertahankan loyalitas konsumen, hendaknya wardah lebih meningkatkan desain dan inovasi produk lipstik nya sehingga wardah terus berkembang dan selalu mengeluarkan produk yang diinginkan konsumen dan lebih up to date terhadap model dan inovasi nya sehingga konsumen tetap membeli lipstik wardah karena semakin baik desain dan inovasi produk maka akan berpengaruh terhadap loyalitas konsumen.

\section{DAFTAR PUSTAKA}

Abdullah, T., \& Tantri, F. (2015). Manajemen Pemasaran. Depok: PT Raja Grafindo Persada.

Almana, L. O., Sudarmanto, \& Suardi, I. (2018). Tata Kelola Perguruan Tinggi Berbasis Akreditasi. Yogyakarta: Dee publish. 
Anggraini, L. N., Kustiyah, E., \& Sudarwati. (2019, Juni). Pengaruh Kualitas, Harga dan Citra Produk terhadap Kepusan Pelanggan pada Produk Kosmetik Wardah (Studi pada Mahasiswi Fakultas Ekonomi Islam Batik Surakarta). EKOBIS: Jurnal Ilmu Manajemen dan Akuntansi, 7(1), 46-58.

Ansah, A. (2017). Pengaruh Desain Produk, Promosi, dan Citra Merek Terhadap Keputusan Pembelian Sepatu Nike Pada Pelanggan Sport Station Solo. Amwaluna: Jurnal Ekonomi dan Keuangan Syariah, 1(2), 178-189.

Ayuningtyas, R. (2016). Analisis Pengaruh Promosi, Desain Produk, dan Kelompok Referensi terhadap Keputusan Pemebelian dengan Citra Merek sebagai Variabel Intervening. Prosiding Seminar Nasional Multi Disiplin Ilmu \& Call for Papers UNISBANK (SENDI_U) ke-2 (pp. 844-852). Semarang: Unisbank.

Dwi Putra, M. C., \& Ekawati, N. W. (2017, Maret). Pengaruh Inovasi Produk, Harga, Citra Merek Dan Kualitas Pelayanan Terhadap Loyalitas Pelanggan Sepeda Motor Vespa. E-Jurnal Manajemen, 6(3), 1674-1700.

Fitriani, V., \& Sharif, O. O. (2018). Analisis Faktor Yang Mempengaruhi Loyalitas Merek Konsumen Pada Produk Kosmetik. e-Proceeding of Management. 5, pp. 90-95. Universitas Telkom.

Gitosudarmo, I. (2012). Manajemen Pemasaran (2 ed.). Yogyakarta: Penerbit BPFE.

Griffin, J. (2010). Customer Loyalty. Jakarta: Erlangga.

Herlambang, S. (2014). Basic Marketing (Dasar-Dasar Pemasaran). Cetakan Pertama. Yogyakarta: Gosyen Publishing.

Highlight Media. (2018, November 7). 10 Merek Kosmetik Lokal Indonesia Paling Favorit Untuk Paras Cantikmu. Retrieved from Highlight.ID: https:/highlight.id/daftar-brand-merek-produk-kosmetiklokal-indonesia-favorit-terkenal-populer-pilihan-makeup-kecantikan/

Husain, T. (2019, December 29). An Analysis of Modeling Audit Quality Measurement Based on Decision Support Systems (DSS). European Journal of Scientific Exploration, 2(6), 1-9.

ICSA. (2019). WINNER ICSI 2016-2017. Retrieved from Indonesian Customer Satisfaction Award: http://icsa-indo.com/winner/icsa_2016.html | http://icsa-indo.com/winner/icsa_2017.html

ika/JPC. (2017, Agustus 13). RI Bidik Peluang Besar Industri Kosmetik dan Kecantikan. (M. Syadri, Editor) Retrieved from Bisnis: https://www.jawapos.com/ekonomi/bisnis/13/08/2017/ri-bidik-peluangbesar-industri-kosmetik-dan-kecantikan/

Khairani, R., Siregar, C. A., Hutabalian, R. H., \& Karolina, I. I. (2019, Juli-Desember). Pengaruh Harga dan Kualitas Pelayanan Terhadap Kepuasan Konsumen Pada PT. MATAHARI PUTERA PRIMA (Hypermart). Jurnal Manajemen, 5(2), 129-136.

Kotler, Philip T., Keller, Kevin Lane. (2016, December). Marketing Management (15 ed.). New Jersey: Pearson Prentice Hall Inc.

Lovelock, C., \& Wirtz, J. (2011). Pemasaran Jasa Perspektif(7 ed.). Jakarta: Erlangga.

Lupiyoadi, R. (2013). Manajemen Pemasaran Jasa: Berbasis Kompetensi (3 ed.). Jakarta: Salemba Empat.

Maulana, B. R. (2019). Pengaruh kualitas pelayanan, kualitas produk, harga terhadap loyalitas konsumen CV. Usaha bersama grafika melalui kepuasan konsumen. Surabaya: UIN Sunan Ampel.

Molle, M. A., Mandey, S. L., \& Kojo, C. (2019, Januari). Pengaruh Kepuasan Konsumen Terhadap Loyalitas Konsumen Pada Royal's Resto and Fuction Hall Dikota Ternate. Jurnal EMBA: Jurnal Riset Ekonomi, Manajemen, Bisnis dan Akuntansi, 7(1), 871-880. 
Nurbani, A., Mulyanto, H., \& Wardani, M. K. (2019, Desember). Pengaruh Bauran Pemasaran Terhadap Kepuasan dan Kepercayaan Serta Dampaknya Pada Loyalitas Konsumen. Jurnal Manajemen Kewirausahaan, 16(2), 109-120.

Purba, T. P. (2017). Manajemen Pemasaran. Jakarta: Mitra Wacana Media.

Rahayu, E. M. (2016, Juni 16). Wow, Indonesia Pasar Pertumbuhan Utama Industri Kecantikan ASEAN. Retrieved from SWA - Strategy: https://swa.co.id/swa/business-strategy/wow-indonesia-pasarpertumbuhan-utama-industri-kecantikan-asean

Sani, A., \& Maharani, V. (2013). Metodologi Penelitian Manajemen Sumber Daya Manusia (Teori, Kuesioner dan Analisis Data), Cetakan Ke-2. Malang: UIN MALIKI Press.

Santoso, E. B., \& Samboro, J. (2017). Pengaruh Promosi Penjualan dan Inovasi Produk Terhadap Keputusan Pembelian Dan Dampaknya Terhadap Loyalitas Pelanggan. Adbis: Jurnal Administrasi dan Bisnis, 11(1), 1-8.

Sinurat, E. S., Lumanauw, B., \& Rori, F. (2017). Pengaruh Inovasi Produk, Harga, Citra Merek Dan Kualitas Pelayanan Terhadap Loyalitas Pelanggan Mobil Suzuki Ertiga. Jurnal EMBA: Jurnal Riset Ekonomi, Manajemen, Bisnis dan Akuntansi, 5(2).

Sugiyono. (2016). Metode Penelitian Kombinasi (Mixed Methods). (M. Sutopo, Ed.) Bandung: CV. Alfabeta.

Susilawati, D. (2016, Juni 18). Indonesia Berpeluang Besar di Industri Kecantikan. Retrieved from Republika Ekonomi: https://www.republika.co.id/berita/ekonomi/makro/16/06/18/o8xfl1-indonesiaberpeluang-besar-di-industri-kecantikan

Tjiptono, F. (2015). Pemasaran Jasa- Prinsip, Penerapan, dan Penelitian. Yogyakarta: Andi Offset.

Wahyu, D. A., \& Gorda, A. E. (2019, Desember). Kualitas Produk, Kualitas Pelayanan Terhadap Word Of Mouth Dengan Kepuasan Konsumen Dan Loyalitas Pelanggan Sebagai Variabel Intervening. Jurnal Ilmiah Manajemen dan Bisnis, 2(2), 324-336.

Wahyuni, E. (2019). Analisis Faktor-faktor Yang Mempengaruhi Loyalitas Konsumen dengan Kepuasan Konsumen Sebagai Variabel Intervening Pada Toko Roti Aroma Medan. Accumulated Journal (Accounting and Management Research Edition, 1(2), 171-182.

Wardah Kosmetik. (2019). Wardah "Feel the Beauty". Retrieved from https://www.wardahbeauty.com/

Widiyanto, I. (2008). Pointers: Metodelogi Penelitian. Semarang: BP UNDIP. 